\title{
Nutritional status and chemotherapy-associated toxicity in patients with cervical cancer
}

\section{Emigdio Jaimes-Alpízar ${ }^{1,3, *}$, Eva María Gómez-García², Mario Ángel Rosas-Sánchez ${ }^{3}$, Diana Yolanda Reyes-Barretero ${ }^{1,3}$ and Marlid Cruz-Ramos ${ }^{2}$}

${ }^{1}$ Department of Clinical Nutrition; ${ }^{2}$ Department of Medical Oncology, State Oncology Center, ISSEMyM; ${ }^{3}$ Faculty of Medicine, Autonomous University of the State of Mexico, Mexico

Received for publication: 5 July 2016; accepted for publication: 25 February 2017

Available online: 6 November 2017

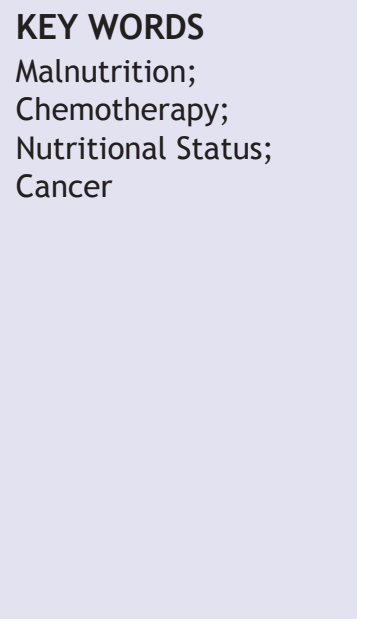

\begin{abstract}
Introduction: Cervical cancer (CC) is a public health problem; it is the second most common cause of cancer in Mexico and the third cause of death worldwide. Malnutrition in the cancer patient is present in $80-90 \%$ of cases of advanced disease. Objective: To analyze the relationship of the nutritional status of patients with clinical Stage IV and recurrent CC with palliative chemotherapy-associated toxicity. Materials and methods: This was a prospective, descriptive, and observational study. Patients with clinical Stage IV CC recurring on palliatio ve chemotherapy were recruited. Nutritional status was assessed before treatment as welt as its relationship with toxicity. Associations between qualitative categorical variables were searched for with Spearman's correlation, and statistically significant differences $(p<0.05)$ for dichotomous variables were looked for using Fischer's exact test. Results: A total of 17 patients were included, out of which $5(29.4 \%)$ had normal nutritional status, 8 patients $(47 \%)$ had moderate malnutrition, and 4 patients $(23.5 \%)$ had severe malnutrition. A positive correlation was found between the degree of malnutrition and the presence of diarrhea (rho = 0.626), nausea $($ rho $=0.556)$, and hypoalbuminemia $(r h o=0.559)$. Conclusions: Nutritional status before chemotherapy was shown to be highly important, since a malnutrition status implies highe toxicity by the treatment, which entails an increase in malnutrition for the next chemotherapy session as well as hospital readmissions. (creativecommons.org/licenses/by-nc-nd/4.0/).
\end{abstract}

*E-mail for correspondence: emigdio.jaimes@yahoo.com (E. Jaimes-Alpízar) 


\section{INTRODUCTION}

Cervical cancer (CC) is a public health problem. It is the second most common cause of cancer in Mexico and the third cause of death worldwide. It accounts for $9 \%(529,800)$ of total new cancer cases and $8 \%(275,100)$ of total cancer-related deaths in women in 2008. Unfortunately, it affects women with economic, social, and cultural disadvantages, and therefore, it is more common in developing countries, where $85 \%$ of cases are recorded ${ }^{1}$. Risk factors associated with this type of cancer include age, human papillomavirus infection, multiple sexual partners, vaginal parity, and low socioeconomic status, among others ${ }^{2}$.

$\mathrm{CC}$ is currently staged according to the International Federation of Gynecology and Obstetrics guidelines ${ }^{3}$, where the advanced or metastatic disease is regarded as recurrent or persistent clinical Stage IVB, with survival probability for these patients ranging from $15 \%$ to $30 \%{ }^{4}$. Most commonly used chemotherapeutic agents for the treatment of CC are hydroxyurea, cisplatin, 5-fluorouracil, carboplatin, oxaliplatin, mitomycin $\mathrm{C}$, epirubicin, topotecan, and irinotecan, among others ${ }^{5}$. In metastatic disease (clinical Stage IVb), the indicated treatment is based on different chemotherapy regimens using cisplatin, carboplatin, and paclitaxel $^{4}$.

Malnutrition is a common problem in cancer patients that is present in $15-20 \%$ at tumor diagnosis and in up to $80-90 \%$ in cases of advanced disease ${ }^{6,7}$. An undernourishment status is associated with poorer response to chemotherapy and worse tolerance (increased toxicity), since on such clinical conditions there is a decrease of circulating proteins, which precludes drugs adequately binding to them, thus altering their half-life periods and pharmacokinetic characteristics ${ }^{8}$. The appearance of symptoms depends on factors such as the type of used drug, the dose, and duration as well as each patient's individual susceptibility, which is influenced by previous clinical and nutritional status 9 . Most common symptoms include diarrhea, which, depending on severity, can even cause treatment discontinuation ${ }^{10}$. Every nutritional intervention must start with an appropriate nutritional assessment of the patient ${ }^{11}$, with the purpose of this evaluation being to identify patients with malnutrition or at risk of experiencing it at some moment of their evolution. This identification enables adequate monitoring to be able to prevent and/or treat malnutrition and to reduce adverse effects of antitumor therapy and to improve the quality of life ${ }^{12}$.

For this reason, it is important for nutritional status assessment to be carried out since the start or during treatment. Nutritional status patient-generated subjective global assessment (PG-SGA) is a quick and reliable tool that allows for patients with malnutrition or at risk of malnutrition to be identified ${ }^{13}$. This nutritional assessment method has been approved by different international oncology and nutrition societies such as the American Dietetic Association, the Clinical Guide to Oncology Nutrition, ${ }^{14}$ and in Spain, with modifications by the Spanish Society of Basic and Applied Nutrition (Sociedad Española de Nutrición Básica y Aplicada $)^{14,15,16}$. The purpose of the present study is to analyze the relationship of the nutritional status of patients with clinical Stage IV CC with the toxicity associated with the treatment with palliative chemotherapy.

\section{MATERIALS AND METHODS}

This was a prospective, descriptive, and observational study where patients older than 18 years diagnosed with clinical Stage IV and recurrent CC treated with palliative chemotherapy were selected. Nutritional status was assessed by means of the PG-SGA. Data were collected, and toxicity symptoms such as nausea, vomiting, diarrhea, leukopenia, lymphopenia, and hypoalbuminemia were assessed using the CTCAE v 4.03 criteria at the next chemotherapy cycle. Associations between categorical quantitative variables were searched for with Spearman's correlation as well as statistically significant differences $(p<0.05)$ for dichotomous variables using Fischer's exact test.

\section{RESULTS AND DISCUSSION}

A total of 17 patients were included, out of which $4(23.5 \%)$ are ISSEMyM beneficiaries and 13 (76.47\%) are covered by the Seguro Popular (People's Insurance). The mean age was 56.1 years \pm 12.75 (standard deviation). In the entire sample, 5 patients $(29.4 \%)$ had normal nutritional status, 8 patients (47\%) had moderate malnutrition, and 4 patients (23.5\%) had severe malnutrition.

Associations were sought between nutritional status (independent variable) and the nausea, vomiting, diarrhea, leukopenia, lymphopenia, neutropenia, and hypoalbumine mia variables (dependent variables) by calculating Spear:man's correlation coefficient $\left(r_{s}\right)$ for categorical variables, which required for nutritional status to be categorized as normal, moderate malnutrition, and severe malnutrition. Similarly, the nausea, vomiting, diarrhea, constipation, leukopenia, lymphopenia neutropenia, and hypoalbuminemia variables were categorized as grade 1,2 , and 3 .

After variables were categorized, the Rho coefficient was obtained to determine correlations between the depent dent and independent variables. The magnitude of association was categorized according to the Rho coefficient value as no correlation $\left(r_{s}=0-0.19\right)$, low correlation $\left(r_{s}=0.20\right.$ $0.39)$, moderate correlation $\left(r_{s}=0.4-0.59\right)$, good correlation $\left(r_{s}=0.60-0.79\right)$, and very good correlation $\left(r_{s}=0.80-1.0\right)$, with correlation being positive (direct) when the coefficient value is negative, and negative (inverse) with r-coefficient negative values.

Positive and moderate correlation was found between the degree of malnutrition and the presence of diarrhea $\left(r_{s}=0.626\right)$, nausea $\left(r_{s}=0.556\right)$, and hypoalbuminemia $\left(r_{s}=0.559\right)$, and low, but positive correlation between the degree of malnutrition and the presence of vomiting $\left(r_{s}=0.242\right)$, leukopenia $\left(r_{s}=0.267\right)$, and lymphopenia $\left(r_{s}=0.262\right)$, respectively (Table 1$)$.

Once these factors whose presence appeared to be associated with the degree of malnutrition of the studied patients were identified, converting our dependent variables into dichotomous variables (present/absent) was required to find out if these associations were statistically significant $(p<0.05)$ by means of Fischer's exact test, since the small size of our sample would make the analysis of associations between each variable's different degrees impossible. 
Table 1. " $r$ " correlation coefficient for nutritional status (normal, malnutrition, serious malnutrition) vs. nausea, vomiting, diarrhea, leukocytopenia, lymphocytopenia, neutropenia, and hypoalbuminemia

\begin{tabular}{lc}
\hline Variable & " $r_{s}$ " coefficient \\
\hline Nausea & 0.556 \\
Vomiting & 0.242 \\
Diarrhea & 0.626 \\
Leukopenia & 0.267 \\
Lymphopenia & 0.262 \\
Neutropenia & 0.107 \\
Hypoalbuminemia & 0.559 \\
\hline
\end{tabular}

Among the obtained results, only the fact that malnutrition was significantly associated with hypoalbuminemia stands out (relative risk $[R R]=2.4 ; 95 \%$ confidence interval $[\mathrm{Cl}]: 1.22-4.68 ; \mathrm{p}=0.04)$, since there were no cases of hypoalbuminemia in those patients with normal nutritional status, and $58 \%$ of patients with some degree of malnutrition had hypoalbuminemia. The remaining possible associations were not statistically significant (Table 2). According to the obtained results, the presence of nausea and diarrhea is directly associated with malnutrition, and these symptoms worsen as malnutrition status deteriorates, since, in both cases, the $r_{s}$ coefficients found were within the 0.5-0.6 range; however, these associations were not statistically significant when said variables were dichotomized.

Finally, of all studied dependent variables, only hypoalbuminemia showed significantly higher incidence in patients with malnutrition $(\mathrm{RR}=2.4 ; 95 \% \mathrm{Cl}: 1.22-4.68 ; \mathrm{p}=0.04)$, and the degree of hypoalbuminemia had a direct and positive relationship with the degree of malnutrition $\left(r_{s}=0.559\right)$.

Malnutrition status has been described to decrease the response to chemotherapy and increase toxicity ${ }^{7,10,13}$; however, specifically in the studied population, there is no evidence by means of which nutritional status outcomes and treatment response might be contrasted.

\section{CONCLUSIONS}

Malnutrition is highly prevalent in this group of patients (70.1\%). CC is mostly diagnosed in patients referred by the Seguro Popular who, given their socioeconomic conditions, are at high risk to suffer some degree of malnutrition. Malnutrition status was shown to be associated with the presence of diarrhea, nausea, and hypoalbuminemia, which translates into most patients with malnutrition requiring post-chemotherapy hospitalization, which in turn entails additional hospital costs.

The presence of malnutrition, regardless of the degree of severity before treatment, increases the risk for protein malnutrition on the next chemotherapy cycle which, as previously mentioned, reduces treatment efficacy, with response and toxicity, therefore, being more affected in the next chemotherapy cycle.
Table 2. Contingency table for nutritional status and presence of nausea, vomiting, diarrhea, constipation, leukopenia, lymphopenia, neutropenia, and hypoalbuminemia

\begin{tabular}{|c|c|c|c|}
\hline $\begin{array}{l}\text { Nutritional } \\
\text { status }\end{array}$ & $\begin{array}{l}\text { Present } \\
\mathrm{n}(\%)\end{array}$ & $\begin{array}{c}\text { Absent } \\
\text { n (\%) }\end{array}$ & $\mathrm{p}^{*}$ \\
\hline & Nausea & & 0.101 \\
\hline Normal & $1(5.9)$ & $4(23.5)$ & \\
\hline \multirow[t]{2}{*}{ malnutrition } & $9(52.9)$ & $3(17.6)$ & \\
\hline & Vomiting & & 0.515 \\
\hline Normal & $0(0)$ & $5(29.4)$ & \\
\hline \multirow[t]{2}{*}{ malnutrition } & $3(17.6)$ & $9(52.9)$ & \\
\hline & Diarrhea & & 0.261 \\
\hline Normal & $0(0)$ & $5(29.4)$ & \\
\hline \multirow[t]{2}{*}{ malnutrition } & $4(23.5)$ & $8(47.1)$ & \\
\hline & Leukopenia & & 1.00 \\
\hline Normal & $0(0)$ & $5(29.4)$ & \\
\hline \multirow[t]{2}{*}{ malnutrition } & $2(11.8)$ & $10(58.8)$ & \\
\hline & Lymphopenia & & 0.60 \\
\hline Normal & 1 (5.9) & $4(23.5)$ & \\
\hline \multirow[t]{2}{*}{ malnutrition } & $5(29.4)$ & 7 (41.2) & \\
\hline & Neutropenia & & 1.00 \\
\hline Normal & $1(5.9)$ & $4(23.5)$ & \\
\hline \multirow[t]{2}{*}{ malnutrition } & $4(23.5)$ & $8(47.1)$ & \\
\hline & Hypoalbuminemia & & 0.04 \\
\hline Normal & $0(0)$ & $5(29.4)$ & \\
\hline malnutrition & $7(41.2)$ & $5(29.4)$ & \\
\hline
\end{tabular}

*Significance was considered at $p<0.05$ for Fischer's exact test.

\section{ACKNOWLEDGMENTS}

To the ISSEMyM State Oncology Center authorities for authorizing the present study.

\section{DECLARATION OF INTEREST}

The authors declare not having any conflicts of interests.

\section{REFERENCES}

1. Siegel R, Ma J, Zou Z, Jemal A. Cancer statistics, 2014. CA Cancer Clin. 2014;64:9-29.

2. Tirado-Gómez LL, Mohar-Betancourt A, López-Cervantes M, García-Carrancá $A$, Franco-Marina $F$, Borges $G$. Risk factors in invasive cervical cancer among Mexican women. Salud Publica Mex. 2005;47:342-50.

3. Pecorelli S, Zigliani L, Odicino F. Revised FIGO staging for carcinoma of the cervix. Int J Gynaecol Obstet. 2009;105:107-8.

4. Dueñas-González A, Cetina L, Coronel J, Martínez-Baños D. Pharmacotherapy options for locally advanced and advanced cervical cancer. Drugs. 2010;70:403-32.

5. Cetina L. Radiosesibilizantes en cáncer cervicouterino. Rev Incan. 2006;1:4-29.

6. Fernández López MT, Saenz Fernández CA, de Sás Prada MT, et al. Malnutrition in patients with cancer; four years experience. Nutr Hosp. 2013;28:372-81. 
7. Cid Conde L, Fernández López T, Neira Blanco P, Arias Delgado J, Varela Correa JJ, Gómez Lorenzo FF. Hyponutrition prevalence among patients with digestive neoplasm before surgery. Nutr Hosp. 2008; 23:46-53.

8. Murry DJ, Riva L, Poplack DG. Impact of nutrition on pharmacokinetics of anti-neoplastic agents. Int J Cancer Suppl. 1998;11:48-51.

9. García-Luna PP, Parejo Campos J, Pereira Cunill L. Causas e impacto clínico de la desnutrición y caquexia en el paciente oncológico. Nutr Hosp. 2006;21 Suppl 3:10-6.

10. Stringer AM, Gibson RJ, Logan RM, et al. Chemotherapy-induced diarrhea is associated with changes in the luminal environment in the DA rat. Exp Biol Med (Maywood). 2007;232:96-106.

11. Cerezo L. Diagnóstico del estado nutricional y su impacto en el tratamiento del cáncer. Oncología. 2005;28:29-134.
12. Arends J, Bodoky G, Bozzetti $F$, et al. ESPEN guidelines on enteral nutrition: Non-surgical oncology. Clin Nutr. 2006;25:245-59.

13. Martínez Roque VR. Valoración del Estado de nutrición en el paciente con cáncer. Cancerología. 2007;2:315-26.

14. Ottery FD. Patient-Generated subjective global assessment. In: McCaIlum PD, Polisena CG, editors. The Clinical Guide to Oncology Nutrition. Chicago: The American Dietetic Association; 2000.

15. Marín Caro MM, Gómez Candela C, Castillo Rabaneda R, et al. Evaluación del riesgo nutricional e instauración de soporte nutricional en pacientes oncológicos, según el protocolo del grupo español de Nutrición y Cáncer. Nutr Hosp. 2008;23:458-68.

16. Grupo de Trabajo de la Sociedad Española de Nutrición Básica y Aplicada (SENBA). Valoración Nutricional. En: Candela CG, Coordinador; editors. Pacientes Neoplásicos Adultos en Intervención Nutricional en el Paciente Oncológico Adulto. Barcelona: Glosa S.L; 2003. p. 35-43. 